\title{
Postal survey of bronchoscopic practice by physicians in the United Kingdom
}

\author{
FG SIMPSON, AG ARNOLD, A PURVIS, PW BELFIELD MF MUERS, NJ COOKE \\ From the Department of Respiratory Medicine and the Pharmacy, General Infirmary, and the Department of \\ Respiratory Medicine, Killingbeck Hospital, Leeds
}

ABSTRACT In 1983 a postal survey of the bronchoscopic practice of chest physicians in the United Kingdom produced a $90 \%$ response rate. Two hundred and thirty one physicians were carrying out bronchoscopy; they had performed about 40000 bronchoscopies in the preceding year, $87 \%$ of these being fibreoptic procedures with topical anaesthesia. The mortality rate of fibreoptic bronchoscopy was $0.04 \%$, with a $0.12 \%$ incidence of major complications. Transbronchial biopsy carried both an appreciably higher mortality rate of $0.12 \%$ and a major complication rate of $2.7 \%$. There is wide variation in the use and choice of sedative drugs for fibreoptic bronchoscopy. Many of the drug combinations could be criticised on pharmacological grounds. The mean dose of lignocaine was $342 \mathrm{mg}$, most operators exceeding the usual maximum recommended dose; but adverse reactions were rare. Routine supplemental oxygen was given by only $18 \%$ of bronchoscopists. Basic resuscitation equipment was often inadequate. Radiological screening was used for transbronchial lung biopsy by $53 \%$ of respondents and significantly reduced the incidence of pneumothorax from $2.9 \%$ to $1.8 \%$. Both the number of bronchoscopies performed and the complication rate were higher than previous estimates. Bronchoscopists should re-examine their policy on drugs and safety precautions to minimise the risks of the procedure.

Rigid bronchoscopy still has a role in the diagnosis and management of massive haemoptysis and stridor from large airways obstruction. Since its introduction in 1967 the fibreoptic bronchoscope has, however, become the instrument most widely used for routine diagnostic purposes in the United Kingdom. The principal advantages are ease of insertion without the need for general anaesthesia and an increased range of view of the bronchial tree. ${ }^{1}$

There have been two retrospective studies of the frequency and complications of fibreoptic bronchoscopy from the United States. In 1974 Credle et al reported a mortality rate of $0.01 \%$ and a major complication rate of $0.08 \%$ in 24501 bronchoscopies from 192 centres. $^{2}$ In 1976 a similar survey of 48000 procedures gave a mortality rate of $0.02 \%$ with a $0.3 \%$ incidence of major complications. ${ }^{3}$ There have

Address for reprint requests: Dr FG Simpson, Leeds Chest Clinic, 74 New Briggate, Leeds LS7 4RB.

Accepted 14 October 1985 been three smaller prospective studies. From the United States Pereira et al reported a mortality of $0.1 \%$ and a major complication rate of $1.7 \%$ in 908 bronchoscopies ${ }^{4}$ and Dreison et al gave figures of $0.5 \%$ and $5 \%$ respectively for 205 procedures. $^{5} \mathrm{~A}$ study from the Soviet Union of 1146 fibreoptic bronchoscopies reported zero mortality and a $0.3 \%$ major complication rate, compared with rates of $0.17 \%$ and $1.1 \%$ respectively in 4595 examinations with the rigid bronchoscope. $^{6}$

There is little information about bronchoscopic practice in the UK. It was estimated in $1974^{7}$ that 15000 patients a year in the UK might require bronchoscopy. The studies that are available ${ }^{8-11}$ are small and from single centres, and tend to concentrate on diagnostic yield rather than complications. It was concluded that there was a need for a larger scale survey of bronchoscopic practice by chest physicians in the UK, particularly to obtain data about the risks of the procedure. This paper reports the result of a postal survey of medical bronchoscopic practice in the UK in which an attempt was made to contact all physicians practising bronchoscopy. 
Table 1 Special procedures performed through the fibreoptic bronchoscope

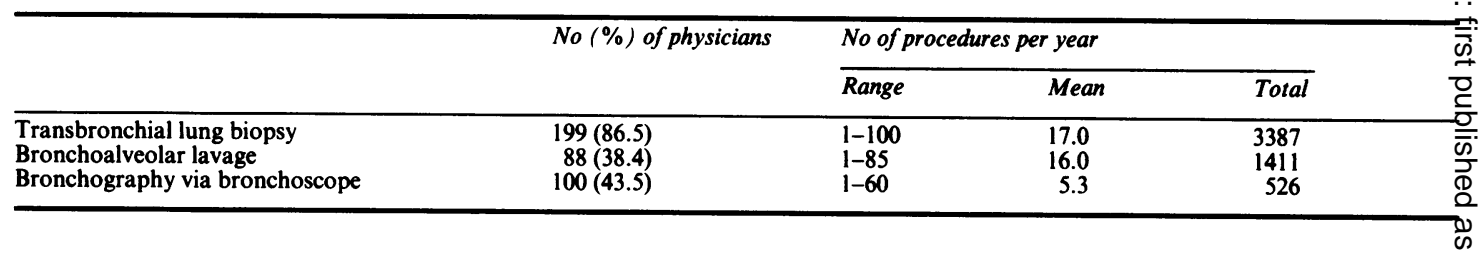

\section{Methods}

A questionnaire was sent to 440 consultant physicians in the United Kingdom who were thought likely to be performing bronchoscopy. These comprised all currently practising consultant physician members of the British Thoracic Society. Data were recorded on the number of procedures performed, endoscopic techniques, use of sedative and local anaesthetic drugs, safety precautions, and deaths and major complications. Details of all reported deaths and major complications were confirmed by direct telephone communication with the physicians concerned. Major complications were defined on the questionnaire as those which in the opinion of the clinician concerned were life threatening or which required urgent therapeutic intervention (such as blood transfusion or insertion of an intercostal drainage tube.

Statistical analysis was by $\chi^{2}$ tests.

\section{Results}

Four hundred and forty questionnaires were distributed and completed forms from 399 physicians were received, a $90 \%$ response rate. Of these 399 physicians, 231 were performing bronchoscopy.

Four physicians $(2 \%)$ used the rigid bronchoscope exclusively, $20(9 \%)$ performed both rigid and fibreoptic bronchoscopy, $19 \quad(8 \%)$ performed fibreoptic bronchoscopy by introducing the fibreoptic through the rigid instrument, and $188(81 \%)$ used the fibreoptic instrument only. The total number of bronchoscopies performed by physicians during the year surveyed (1983) was reported as 39564 . Of these, $35628(90 \%)$ were fibreoptic bronchoscopies, 2220 $(5.6 \%)$ were performed with the fibreoptic instrument via the rigid bronchoscope, and $1716(4.3 \%)$ were rigid bronchoscopies. In addition to these bronchoscopies, 58 physicians indicated that they referred some of their patients to thoracic surgeons fo $\vec{D}$ bronchoscopy; these referrals resulted in an estimated 4104 rigid bronchoscopies performed by surgeons. $\omega$

Of the 227 physicians using the fibreoptic broncho scope, $190(84 \%)$ introduced the instrument by the transnasal route, $19(8 \%)$ via an endotracheal tube nine $(4 \%)$ through a rigid bronchoscope, and nine $(4 \%)$ through the mouth.

Eighty seven per cent of the fibreopti $\vec{G}$ bronchoscopies reported were performed with topica干 anaesthesia, with or without additional sedation.

Table 1 shows the number of physicians pero forming special procedures through the fibreoptic bronchoscope and the reported numbers of pro\% cedures per annum. Most physicians $(86.5 \%)$ perforn transbronchial lung biopsy at a mean rate of 17 pro cedures a year, though the frequency varied considerably - some physicians performing up to 100 transbronchial biopsies annually. Bronchoalveolag lavage was performed by only $38 \%$ of physicians an bronchography through the bronchoscope by $44 \%=$ (In both cases the frequency varied considerably between different centres.)

There were 17 deaths and 137 major complication following bronchoscopy. Among the 34461 reported fibreoptic bronchoscopies (without transbronchia biopsy) there were 13 deaths and 44 major complia cations, compared with four deaths and 93 majos complications in the estimated 3387 transbronchia biopsies (table 2). This gives a mortality rate of $0.04 \%$ for simple fibreoptic bronchoscopy and $0.12 \%$ fo transbronchial biopsy $(p<0.05)$ and an incidence o 6 major complications of $0.12 \%$ for fibreoptic bronchoscopy and $2.7 \%$ for transbronchial biops $(\mathrm{p}<0.0001)$.

Analysis of the apparent causes of the deaths an $\mathbb{R}^{\circ}$ major complications (tables 3 and 4) showed that all four deaths and 91 of the 93 complications than followed transbronchial biopsy were due to

Table 2 Deaths and major complications of fibreoptic bronchoscopy with and without transbronchial biopsy

\begin{tabular}{|c|c|c|c|c|}
\hline \multirow[t]{2}{*}{ Procedure } & \multirow[t]{2}{*}{ No } & \multicolumn{2}{|l|}{ No $(\%)$ of } & \\
\hline & & deaths & major complications & \\
\hline $\begin{array}{l}\text { Bronchoscopy alone } \\
\text { Transbronchial biopsy } \\
\text { Total }\end{array}$ & $\begin{array}{r}34461 \\
3387 \\
37848\end{array}$ & $\begin{array}{r}13(0.04 \%) \\
4(0.12 \%) \\
17(0.04 \%)\end{array}$ & $\begin{array}{c}44(0.12 \%) \\
93(2.7 \%) \\
137(0.36 \%)\end{array}$ & 2 \\
\hline
\end{tabular}


Table 3 Apparent causes of deaths after simple fibreoptic bronchoscopy (FOB) and after fibreoptic bronchoscopy with transbronchial biopsy $(T B B)$

\begin{tabular}{lcl}
\hline & $F O B$ & $T B B$ \\
\hline Haemorrhage & 2 & 3 \\
Cardiovascular disease & 5 & $\overline{1}$ \\
Advanced neoplasia & 2 & - \\
Bronchospasm & 2 & - \\
Aspiration pneumonia & 1 & $\overline{2}$ \\
Non-specific & 1 & $1 / 2^{*}$ \\
Pneumothorax & $\overline{4}$ & 4 \\
Total & 13 &
\end{tabular}

*In one case both neoplasia and a pneumothorax were thought to be contributing.

haemorrhage or pneumothorax, while only two of 13 deaths and 10 of 44 complications after simple bronchoscopy were due to these biopsy related complications. Thirty one of the 74 pneumothoraces reported as major complications required intercostal tube drainage. Of the other complications, the most frequent was respiratory depression. There were two serious reactions to local anaesthetic. The most common cause of death after straightforward fibreoptic bronchoscopy was myocardial infarction or left ventricular failure. The death listed as "non-specific" occurred after a general anaesthetic. Six of the 17 patients who died had bronchial neoplasms, two had leukaemia (both dying of haemorrhage after transbronchial lung biopsy), and one had pulmonary tuberculosis. There were no significant associations between the incidence of death and major complications and the type of bronchoscopic practice, the numbers of bronchoscopies performed by each unit, or the type of hospital in which the procedure was performed. There was an apparently higher incidence of deaths and major complications in teaching hospitals than in district general hospitals, but this probably reflected the fact that patients in teaching hospitals were 1.64 times more likely to undergo transbronchial biopsy at the time of bronchoscopy than patients in district general hospitals.

There were no reported deaths or major complications associated with bronchoalveolar lavage or bronchography.

\section{PREOPERATIVE ASSESSMENTS}

One hundred and fifty physicians $(66 \%)$ routinely performed some assessment of respiratory function (for example, $\mathrm{FEV}_{1}$, blood gas tensions) before bronchoscopy. Eighty three (37\%) enforced a "nil by mouth" policy from the night before the procedure, $108(48 \%)$ for four hours or more but not overnight, and $33(15 \%)$ for less than four hours. The policies on fluid restriction were not influenced by the sedation used for the procedure. Routine investigations before transbronchial lung biopsy included a platelet count by 150 physicians $(75 \%)$, prothrombin time or clotting screen by $129(65 \%)$, blood grouping by 43 $(22 \%)$, and cross matching of blood by $13(6.5 \%)$.

\section{USE OF SEDATIVE DRUGS}

Of the 227 physicians performing fibreoptic bronchoscopy, $13(6 \%)$ did so without routinely using any sedative drugs, $105(47 \%)$ used a premedication injection of sedative given 30 minutes or more before the procedure, $39(17 \%)$ used intravenous sedatives at the time of the procedure, $43(19 \%)$ used both intravenous drugs and premedication, and $26(12 \%)$ gave a general anaesthetic. The usual sedation practice of one respondent was not stated.

Further details of the sedative drugs used were provided by 187 respondents (table 5). Of the 103 physicians using a single drug, $80(78 \%)$ gave an opiate, 76 physicians using an intramuscular injection of morphine or papaveretum as a premedication while four used intravenous synthetic opiates such as fentanyl at the time of the procedure. Of the 22 physicians using a benzodiazepine alone, 12 gave the drug intravenously at the time of the procedure, three used an oral benzodiazepine as a premedication, and seven gave an intramuscular injection as a premedication. Most of those using two drugs used either an opiatebenzodiazepine combination or one of the standard neuroleptanalgesic combinations of a short acting opiate with a tranquilliser-for example, phenoperidine and droperidol. Of the 43 operators using the opiate-benzodiazepine combination, 25 gave the opiate as a premedication and one gave an intramuscular premedication injection of benzodiazepine with intravenous opiate at the time of the procedure. In all, 15 operators used benzodiazepines by intramuscular injection despite the variable absorption when they are given by this route. There was no association between overall complications and any particular sedative combination. Information relating to sedation

Table 4 Apparent causes of major complications after fibreoptic bronchoscopy alone (FOB) and fibreoptic bronchoscopy with transbronchial biopsy (TBB)

\begin{tabular}{|c|c|c|c|}
\hline & $F O B$ & $T B B$ & \\
\hline $\begin{array}{l}\text { Pneumothorax } \\
\text { Haemorrhage }\end{array}$ & $\begin{array}{r}0 \\
10\end{array}$ & $\left.\begin{array}{l}74 \\
17\end{array}\right\}$ & $\begin{array}{l}\text { "Biopsy } \\
\text { related" }\end{array}$ \\
\hline $\begin{array}{l}\text { Respiratory depression } \\
\text { Vasovagal episode } \\
\text { Pulmonary oedema } \\
\text { Arrhythmia } \\
\text { Bronchospasm } \\
\text { Laryngospasm } \\
\text { Reaction to local anaesthetic } \\
\text { Septicaemia } \\
\text { Stuck cytology brush } \\
\text { Upper respiratory obstruction } \\
\text { requiring tracheostomy }\end{array}$ & $\begin{array}{r}12 \\
4 \\
4 \\
4 \\
3 \\
2 \\
2 \\
1 \\
1 \\
1 \\
1\end{array}$ & $\begin{array}{l}2 \\
0 \\
0 \\
0 \\
0 \\
0 \\
0 \\
0 \\
0 \\
0\end{array}$ & \\
\hline Total & 44 & 93 & \\
\hline
\end{tabular}


Table 5 Use of sedative drugs for fibreoptic bronchoscopy by 200 physicians

\begin{tabular}{lll}
\hline No of drugs & Drug & No of physicians \\
\hline 0 & No sedative used routinely & 13 \\
1 & Opiate* & 80 \\
& Benzodiazepine & 22 \\
& Droperidol & 1 \\
2 & Opiate* and benzodiazepine & 43 \\
& Neuroleptanalgesia & 21 \\
& Cyclimorph & 3 \\
& 2 benzodiazepines & 1 \\
& 2 opiates & 1 \\
3 & Neuroleptanalgesia and benzodiazepine & 7 \\
& Neuroleptanalgesia and antihistamine & 1 \\
& Neuroleptanalgesia and opiate & 4 \\
& Opiate and 2 benzodiazepines & 2 \\
4 & Amytal, phenoperidine, droperidol, & 1 \\
\hline
\end{tabular}

*Morphine, diamorphine, codeine, or papaveretum.

was available for 10 of the reported episodes of life threatening respiratory depression. Seven of these occurred in units using intravenous sedatives; three occurred after premedication alone $(0.2>p>0.1)$.

An anticholinergic drug was used by 174 physicians $(87 \%), 142(71 \%)$ using atropine and $32(16 \%)$ scopolamine. In $89 \%$ of cases the anticholinergic agent was given at least 30 minutes before operation by intramuscular injection.

\section{LOCAL ANAESTHESIA}

Details of local anaesthetic usage were available for 214 bronchoscopists. One hundred and ninety eight $(92 \%)$ used lignocaine, $15(7 \%)$ cocaine, and $1(0.5 \%)$ prilocaine. Three physicians added adrenaline to the local anaesthetic. The mean dose of lignocaine used has been calculated for both the midpoint and the maximum of the dosage range quoted by respondents. For the midpoint the mean dose was 342 (SD 165, (range 100-960) $\mathrm{mg}$ ) and for the maximum of the dosage range 368 (SD 185, range 100-1180) $\mathrm{mg}$. The vast majority of operators used a spray to apply local anaesthetic to the upper airway and injected local anaesthetic solution through the bronchoscope to anaesthetise the vocal cords and lower airways. Cricothyroid puncture was used by 29 bronchoscopists $(15 \%)$.

OXYGEN AND POSTOPERATIVE OBSERVATIONS

Supplemental oxygen was given routinely by $18 \%$ of respondents, but $9.5 \%$ never gave oxygen. Fifty three $(27 \%)$ of operators maintained intravenous access with an indwelling needle or cannula during bronchoscopy. Eating and drinking were prohibited for over four hours after bronchoscopy by $17(8 \%)$ operators, for two to four hours by $127(57 \%)$, and for less than two hours by 78 (35\%). Routine postoperative observation was carried out by 86 physicians $(43 \%)$ and was not related to the policy on sedation.

\section{ADDITIONAL FACILITIES}

Details of resuscitation equipment immediately avail $\frac{\bar{\omega}}{7}$ able in the bronchoscopy suite are given in table $6 \stackrel{\odot}{\circ}$ Facilities for immediate endotracheal intubation were available to $87 \%$ of bronchoscopists but only $68 \%$. had immediate access to a defibrillator and only $42 \%$ to a rigid bronchoscope. Opiate antagonists were $\overrightarrow{\vec{H}}$ immediately available to $88 \%$ of bronchoscopists. $\mathscr{S}^{\omega}$

One hundred and ninety four physicians gave details of radiological screening facilities for trans bronchial lung biopsy. Ninety two physicians (47\%) did not use screening and reported 36 pneumo thoraces in 1234 procedures, an incidence of $2.9 \%$ One hundred and two physicians using radiologicab screening reported significantly fewer pneumothoraces (35 in 1968 procedures, an incidence of $1.8 \%: p<0.05$ ). There was no significant difference in the number of pneumothoraces encountered by bronchoscopists with access to biplane screening ando by those with access only to single plane screening facilities.

\section{Discussion}

A postal questionnaire survey has two importank drawbacks. Firstly, some less successful broncho $\vec{\not}$ scopists may not have replied and, secondly, for some of the data the survey relies on the memory of par? ticipants and some respondents may have been reluc? tant to recall and record deaths or major compli cations. Both factors would lead to an underestimate of the complication rate of the procedure. This may in part account for the lower rates of death and complio cations reported in surveys of this type ${ }^{23}$ than in some prospective surveys. ${ }^{45}$ The low rates of moro tality and morbidity in the published prospective studies are, however, based on small numbers of pro은 cedures and this may account for the apparents difference in mortality rates. ${ }^{4-6}$

Questionnaire surveys can obtain information on large numbers of procedures easily. The $90 \%$ response rate in this study, which compares favour

Table 6 Availability of emergency equipment in the endoscopy area

\begin{tabular}{|c|c|}
\hline & No $(\%)$ \\
\hline $\begin{array}{l}\text { Rigid bronchoscope } \\
\text { Laryngoscope and endotracheal tube } \\
\text { Defibrillator } \\
\text { Balloon catheter } \\
\text { Topical adrenaline } \\
\text { None }\end{array}$ & $\begin{array}{r}82(41.0) \\
174(87.0) \\
136(68.0) \\
54(27.0) \\
133(66.5) \\
17(8.5)\end{array}$ \\
\hline
\end{tabular}


ably with the $77 \%$ and $31 \%$ of previous studies, ${ }^{23}$ and the care with which the lengthy questionnaire was completed by respondents make us feel that the information is likely to be accurate. Postal surveys have the advantage of reflecting nationwide practice rather than results from selected centres.

A major finding of the survey was the much greater number of medical bronchoscopies being performed than was estimated 10 years ago (around 40000 , compared with an estimated 15000 in 1974). The death and major complication rates associated with this large number of bronchoscopies are low, but appreciably higher than were found in the mid 1970s in comparable surveys in the United States. Taken together these observations raised the possibility that bronchoscopies are being performed now on patients who on account of age or general condition may have been considered unfit for the procedures in the past.

A further explanation for a higher overall complication rate than in the 1970s is the greater frequency with which transbronchial lung biopsy is being performed. Previous British studies of small numbers of transbronchial biopsies ${ }^{1213}$ have reported no fatalities. Our figures show a significantly greater risk of death and of major complications with transbronchial biopsy than with straightforward fibreoptic bronchoscopy and the mortality rate is similar to that found in an American survey covering over 5000 procedures. ${ }^{14}$ In this survey the definition of a major complication was left to the judgement of the clinician concerned whereas earlier studies attempted stricter definitions, making comparison of the rate of complications between different surveys difficult. Comparison between complication rates of bronchoscopy with and without transbronchial biopsy within a survey is probable valid and the 20 fold increase in major complications seen with transbronchial biopsy is highly significant. Furthermore, the range of complications after transbronchial biopsy differs from that reported with simple bronchoscopy.

Little information is available about the most appropriate sedation for fibreoptic bronchoscopy despite the observation that respiratory depression associated with use of sedatives is one of the more common complications of the procedure. ${ }^{2}$ Although some authorities maintain that benzodiazepines are inadequate and recommend opiates, ${ }^{1516}$ Rees et al, ${ }^{17}$ in a controlled double blind trial, found no differences between intramuscular papaveretum, diazepam, and atropine alone but did show that intravenous diazepam was preferred to placebo by patients. Dorward et $a l^{18}$ found that bronchoscopists (but not patients) preferred papaveretum to temazepam on the grounds of increased cooperation, but noted that this was achieved at the cost of significant respiratory depression as assessed by arterial blood gas tensions.
In a small single blind study Goroszeniuk et al ${ }^{19}$ found fentanyl and diazepam given intravenously superior to premedication with papaveretum. For gastrointestinal endoscopy diazepam has been found superior to morphine ${ }^{20}$ and as good as the neuroleptanalgesic combination of phenoperidine and droperidol, which was found to produce a rise in end tidal carbon dioxide tension ${ }^{21}$ Opiates have the advantage that adverse effects can be rapidly reversed by naloxone and most bronchoscopists using opiates have this readily available. Neuroleptanalgesia is said to produce good recovery and the patient remains cooperative. The short acting opiates used are, however, potent respiratory depressants and droperidol may prevent the patient from showing distress because of the catatonia like state it may produce. ${ }^{22}$ The necessity for any sedation for fibreoptic bronchoscopy has been questioned ${ }^{23}$ and indeed 13 bronchoscopists in this study did not use sedation routinely.

The choice of sedative drugs and drug combinations is wide. It is illogical on pharmacological grounds to combine different opiates or benzodiazepines. ${ }^{24}$ Regimens based on such combinations and those using three or more sedative drugs seem unnecessarily complex. In view of the morbidity associated with respiratory depression due to oversedation and the conflicting evidence about the most appropriate sedatives for this procedure using as simple a regimen as possible seems sensible.

Routine use of anticholinergic drugs is generally recommended to dry secretions and to prevent bradycardia ${ }^{15162526}$ and there is little variation in their use. The use of local anaesthesia is more contentious. Standard pharmacological sources ${ }^{27} 28$ give $200 \mathrm{mg}$ as the maximum safe dose of lignocaine (though Martindale gives $600 \mathrm{mg}$ for topical use ${ }^{29}$ ). Broncho-scopists generally recommend a maximum of $300 \mathrm{mg} .^{27162530}$ Several studies have, however, shown that toxic blood concentrations are rarely reached during fibreoptic bronchoscopy even when this dose is exceeded. ${ }^{31-33}$ The dose of lignocaine used by respondents in this survey was often over 300 $\mathrm{mg}$ but only two serious reactions to lignocaine were reported. It seems likely that the recommendations are overcautious as much of the local anaesthetic solution is reaspirated through the bronchoscope and is thus not absorbed. Most bronchoscopists apply local anaesthetic in the traditional manner and recently described techniques using a fine tube or nebuliser are not widely used. Cricothyroid puncture is used by $15 \%$ of operators, although patients may find it unpleasant and it is not without risk. ${ }^{34}$ There seems to be little cause for concern about the current use of local anaesthetics for bronchoscopy. Conventional techniques seem satisfactory for most operators and 
problems are rarely seen.

Published recommendations regarding safety precautions for fibreoptic bronchoscopy include a four hour preoperative fast,${ }^{15}$ routine use of supplemental oxygen, ${ }^{27152635-7}$ preoperative assessment of respiratory function, ${ }^{272637}$ availability of cardiopulmonary resuscitation equipment ${ }^{2}$ and a rigid bronchoscope, ${ }^{2637}$ and, for transbronchial biopsy, a preoperative clotting screen 151626 and use of fluoroscopy. ${ }^{16263738}$ There is relatively little in the way of published evidence to support many of these recommendations.

Most bronchoscopists have their patients fasting for four or more hours, but surprisingly few give oxygen routinely despite the known deleterious effects of fibreoptic bronchoscopy on arterial blood gas tensions (the arterial oxygen tension often falling by 2 $\mathrm{kPa}$ or more) $)^{3536}$ and an appeciable minority never use oxygen. There was, however, no significant relationship between reported complications and whether or not oxygen was administered routinely.

The availability of equipment for resuscitation and control of bleeding varied and the proportion of operators performing this invasive procedure without immediate access to cardiac resuscitation equipment was surprising.

Pneumothorax and haemorrhage are the major complications of transbronchial lung biopsy. It has been suggested that use of radiological screening is associated with a lower incidence of pneumothorax ${ }^{38}$ and this is supported by the present findings. There is no published evidence that clotting abnormalities contribute to bleeding after transbronchial biopsy but it would seem prudent to exclude them. Twenty five per cent of operators performed this procedure without a routine clotting screen before operation. The recommendations that transbronchial lung biopsy should be performed under radiological control and preceded by a clotting screen seem sensible.

Fibreoptic bronchoscopy is generally well tolerated, easy to perform and safe. It is important, however that the ease of performance and rarity of complications should not hide the fact that deaths and life threatening complications do occur. Physicians should exercise caution in selection of patients for bronchoscopy and, in view of the widely varying practice shown by the survey, review their use of sedative drugs and the availability of emergency equipment to try to minimise the risks.

We wish to thank Key Med Limited, for financial support, Mrs B Binns of the Department of Community Medicine, University of Leeds, for statistical help, and Mrs K Marsden and Miss Alison Dobbs for secretarial assistance.
References

1 Sackner MA. Bronchofiberoscopy. Am Rev Respir Dis 1975;111:62-88.

2 Credle WF, Smiddy JF, Elliot RC. Complications of fibreoptic bronchoscopy. Am Rev Respir Dis 1974, 109:67-72.

3 Suratt PM, Smiddy JF, Gruber B. Deaths and compli-尺 cations associated with fiberoptic bronchoscopy. Chest్టి 1976;69:747-51.

4 Pereira W, Kovnat DM. Snider GL. A prospective co- $\vec{\circ}$ operative study of complications following flexible fibreoptic bronchoscopy. Chest 1978;73:813-6.

5 Dreison RB, Albert RK, Talley PA, et al. Flexible fiberoptic bronchoscopy in the teaching hospital: yield $\vec{x}$ and complications. Chest 1978;74:144-9.

6 Lukowsky GI, Ovchinnikov AA, Bilal A. Complications of bronchoscopy. Comparison of rigid bronchoscopy under general anesthesia and flexible fibreoptic bronchoscopy under topical anesthesia. Chest $\overrightarrow{\mathrm{o}}$
1981;79:316-21.

7 Anonymous. Safety and fibreoptic bronchoscopy [Edi- torial]. Br Med J 1974; iii:542-3.

8 MacDonald JB. Fibreoptic bronchoscopy today: review of 255 cases. $\mathrm{Br}$ Med J 1975;iii:753-5.

9 Knight RK, Clarke SW. An analysis of the first 3000 fibreoptic bronchoscopies at the Brompton Hospital. B!o $J$ Dis Chest 1979;73:113-20.

10 Stalker R, Ward RL. Hazards of fibreoptic brono choscopy [letter]. Br Med J 1979;1:533.

11 Macfarlane JT, Storr A, Ward MJ, Roderick-Smith WH. Safety, usefulness and acceptability of fibreoptic్ bronchoscopy in the elderly. Age Ageing 1981;10:127-31

12 Stableforth DE, Knight RK, Collins JV, Heard BE Clarke SW. Transbronchial lung biopsy through theo fibreoptic bronchoscope. Br J Dis Chest 1978;72:108-14?

13 Mitchell DM, Emerson CJ, Collins JV, Stableforth DE? Transbronchial lung biopsy with the fibreoptice? bronchoscope: Analysis of results in 433 patients. $\mathrm{Br}$ Dis Chest 1981;73:258-62. 14 Herf SM, Suratt PM. Complications of transbronchia $\underset{\times}{\widehat{~}}$
lung biopsies. Chest 1978;73:759-60.

15 Knight RK. Bronchoscopy and other biopsy techniques In: Emerson P, ed. Thoracic Medicine. London: Butter? worths, 1981:189-205.

16 Clarke SW. Medical bronchoscopy-Using the fibreoptic bronchoscope. In: Besser M, ed. Advanced Medicine. London: Pitman Medical, 1977.

17 Rees PJ, Hay JG, Webb JR. Premedication for fibreoptig bronchoscopy. Thorax 1983;38:624-7.

18 Dorward AJ, Berkin KE, Elliott JA, Stack BHR. A double-blind controlled study comparing temazepans with papaveretum as premedication for fibreoption bronchoscopy. Br J Dis Chest 1983;77:60-5.

19 Goroszeniuk T, Nicholas IH, Marchant P, Turner JAM Johnson NM. Premedication for fibreoptic bronchoscopy: fentanyl, diazepam and atropine compared with papaveretum and lignocaine. $\mathrm{Br}$ Med $\bar{\sigma}$ 1980;281:486.

20 Ludlam R, Bennett JR. Comparison of diazepam and morphine as premedication for gastrointestinal endo scopy. Lancet 1971;ii:1397-9.

21 Nimmo WS, Forrest JAH, Heading RC, Finlaysom NDC, Prescott LF. Premedication for upper gastro $\$$ intestinal endoscopy. Endoscopy 1978;10:183-6.

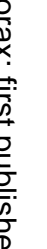


22 Avery GS. Drug treatment. London: Churchill Livingstone, 1980:296-7.

23 Pearce SJ. Fibreoptic bronchoscopy: is sedation really necessary? Br Med J 1980;281:779-80.

24 British National Formulary. No 8. London: Pharmaceutical Press, 1984.

25 Fry WA. Techniques of topical anaesthesia for bronchoscopy. Chest 1978;73, suppl:694-6.

26 Zavala DC. Complications following fiberoptic bronchoscopy. The "good news" and the "bad news." Chest 1978;73:783-5.

27 Pharmaceutical Codex. 11 th ed. London: Pharmaceutical Press, 1979: 493-4.

28 Astra Pharmaceuticals. Data sheet compendium 1984-5. In: Association of British Pharmaceutical Industries, eds. London: Datapharm Publications, 1984:116.

29 Martindale. The extra pharmacopoeia. 28th ed. London: Pharmaceutical Press, 1982:902-8.

30 Perry LB. Topical anaesthesia for bronchoscopy. Chest 1978;73, suppl:691-3.

31 Patterson JR, Blaschke TF, Hunt KK, Meffin PJ. Lignocaine blood concentrations during fibreoptic bron- choscopy. Am Rev Respir Dis 1975;112:53-7.

32 Efthimiou J, Higenbottam T, Holt D, Cochrane GM. Plasma concentrations of lignocaine during fibreoptic bronchoscopy. Thorax 1982;37:68-71.

33 Jones DA, McBurney A, Stanley PJ, Tovey C, Ward JW. Plasma concentrations of lignocaine and its metabolites during fibreoptic bronchoscopy. $\mathrm{Br} J$ Anaesth 1982;54:853-7.

34 Schillaci RF, Iacovoni VE, Conte RS. Transtracheal aspiration complicated by fatal haemorrhage. $N$ Engl J Med 1976;295:488-90.

35 Karetzky MS, Garvey JW, Brandstetter RD. Effect of fiberoptic bronchoscopy on arterial oxygen tension. $N Y$ State J Med 1974;74:62-3.

36 Albertini R, Harrel JH, Kurihara N, Moser KM. Arterial hypoxaemia induced by fiberoptic bronchoscopy. JAMA 1974;230:1666-7.

37 Anonymous. Hazards of fibreoptic bronchoscopy [editorial]. Br Med J 1979;i:212-3.

38 Fulkerson WJ. Fiberoptic bronchoscopy. $N$ Engl J Med 1984;311:511-5. 